\title{
Information security professional perceptions of knowledge-sharing intention in virtual communities under social cognitive theory
}

\begin{abstract}
Knowledge sharing is an important component of knowledge management systems. Security knowledge sharing substantially reduces risk and investment in information security. Despite the importance of information security, little research based on knowledge sharing has focused on the security profession. Therefore, this study analyses key factors, containing attitude, self-efficacy, personal outcome expectation, and facilitating condition, in respect of the information security workers intention to share knowledge. Information security professionals in virtual communities, including the Information Security Professional Association (ISPA), Information Systems Security Association (ISSA), Society of Information Risk Analysts (SIRA), and LinkedIn security groups, were surveyed to test the proposed research model. Confirmatory factor analysis (CFA) and the structural equation modelling (SEM) technique were used to analyse the data and evaluate the research model. The results showed that the research model fit the data well and the structural model suggests a strong relationship between attitude and knowledge sharing intention. Hypotheses regarding the influence of self-efficacy and personal outcome expectation, to knowledge sharing attitude were upheld. Facilitating condition showed significant influences on moderating between attitude and intention.
\end{abstract}

Keyword: Knowledge sharing; Information security; Personal outcome expectation; Selfefficacy; Reasoned action theory; Facilitating condition 